\title{
Rhenium Re 188 BMEDA-labeled Liposomes
}

National Cancer Institute

\section{Source}

National Cancer Institute. Rhenium Re 188 BMEDA-labeled Liposomes. NCI Thesaurus.

Code C118670.

A liposome-based preparation consisting of the beta- and gamma-emitting radionuclide rhenium Re 188 (Re 188) linked to the chelator N,N-bis (2-mercaptoethyl)-N',N'diethylethylenediamine (BMEDA) and encapsulated in liposomes, with potential tumor imaging and antineoplastic activities. Upon intravenous infusion of rhenium Re 188 BMEDA-labeled liposomes, the liposomes selectively target tumor cells, facilitate the retention of the radioisotope by those cells, and cause localized antitumor radiocytotoxicity while sparing surrounding normal, healthy cells. In addition, $\operatorname{Re} 188$ BMEDA-labeled liposomes can be used for imaging purposes. Re 188 has a short half-life and a short path length, which further contribute to limiting the radiotoxicity to the tumor cells. 